\title{
On the sustainability in cyberspace
}

\author{
Xiao-Qiang Pan \\ Institute of Systems Engineering on Engineering Equipment, Beijing, China \\ ${ }^{\dagger}$-mail:panxqcx@sohu.com
}

\begin{abstract}
With the development of Internet, more and more importance is being laid to the threats in cyberspace, which may have a profound effect on sustainable development of cyberspace. This paper aims at establishing a new concept of sustainability in cyberspace. Firstly, traditional sustainability was reviewed. And in the case of cyberspace, a general analysis was given to its status quo as well as the threats in a worldwide perspective. Then the sustainability in cyberspace was defined on the basis of traditional sustainability and above-mentioned analysis. In particular, the conception of sustainability in cyberspace was systematically programmed.
\end{abstract}

Keywords: Cyberspace; Sustainability; System Programming.

\section{Introduction}

In the late $20^{\text {th }}$ century, environmental problems became global in scale. The energy crises demonstrated the extent to which the global community had become dependent on non-renewable energy resources. In the $21^{\text {st }}$ century, there is increasing global awareness of the threat posed by the human-induced greenhouse effect. What we are faced with is not only an economic problem, but need in such aspects as the values, culture and civilization way wider and more profound changes.

With the Internet as the core of the new technology such as information and communications, cyberspace has become the fifth-dimensional space after land, sea, sky, outer space. Cyberspace is deeply influencing the world economy, politics, culture and the development of the society. But we have to face up to various security treats such as cybercrime, cyber bar, cyber terrorism, etc., which may take an outstanding effect on sustainable development of human's modern civilization.

\section{Understanding Sustainability}

Sustainability science is the study of the concepts of sustainable development and environmental science. Sustainability can be defined as the practice of reserving resources for future generation without any harm to the nature and 
other components of it.[1] There is an additional focus on the present generations' responsibility to regenerate, maintain and improve planetary resources for use by future generations. Numerous sustainability standards and certification systems have been established in recent years. These include Organic certification, Rainforest Alliance, Fair Trade, UTZ Certified, Bird Friendly, and the Common Code for the Coffee Community (4C).[2],[3]

\section{Problems in Cyberspace}

The list of problems in cyberspace is long, and spans a wide range of motives and capabilities. At the extreme end there's cyber war: destructive actions by governments during a war. Much more common are the domestic and international criminals who run the gamut from lone individuals to organized crime. They can be very capable and well-funded and will continue to inflict significant economic damage. Hacktivists are a different threat. Their actions range from Internet-age acts of civil disobedience to the inflicting of actual damage. This is hard to generalize about because the individuals and groups in this category vary so much in skill, funding and motivation. This list of potential cyberspace attackers isn't exhaustive. Depending on who you are and what your organization does, you might be also concerned with espionage cyber-attacks by the media, rival corporations or even the corporations we entrust with our data.

All these problems are especially difficult because military and security organizations along with corporations tend to hype particular threats. For example, cyber war and cyber terrorism are greatly overblown as threats -because they result in massive government programs with huge budgets and power -- while cybercrime is largely downplayed.

\section{Conception of the Sustainability in Cyberspace}

\subsection{Definition}

A sustainable cyberspace may be defined as follows: " Targeting establishment of global Internet governance and under the condition that all countries' sovereignty in the cyberspace must be respected, great importance should be laid on such cyberspace aspects as infrastructure strengthening, high and new technologies for various networks, human resource management, international cooperation on counterattacking cyber-threats, sharing web resource between countries, etc., which is expected to promote the overall progress of human civilization". 


\subsection{Conditions}

Besides carrying on the most fundamental condition, i.e., sustainability, a sustainable cyberspace should satisfy three conditions as follows.

(1)Setting a general value: "Community of destiny"

With the rapid development of Internet and information technology, distance between people became narrow. It is possible for people in different areas to communicate with each other unprecedentedly. The earth like a village, and we are the community of destiny. Anyone's misconduct is likely to affect the survival of mankind. Personal interests, national interests, and local interests are subject to whole interests of mankind.

(2)Reaching a common view: "Cyberspace is also human's life supporting system"

For modern people living in the information era, the virtual cyberspace like traditional natural ecological environment is also human's life supporting system. maintaining security of cyberspace or not is related to human's sustainable development. And to tell a truth, nowadays, human's activities of remaking the nature is never inseparable from cyberspace. Cyberspace has been becoming another home, which is virtual but can undoubtedly have profound impact on our traditional physical space.

(3)Standing to an ethics base line: "Anybody has the right to survive and develop by means of cyberspace, but nobody has the right to infringe others' survival or development of contemporary and future generations"

Cyberspace is a newly created civilization of human in the late $20^{\text {th }}$ century. It not only belongs to contemporary generation but also needs to be inherited by future generations. While using resources in cyberspace, others or other countries' interests must not be infringed so as to the sustainability of all the individuals and countries can be protected from threats. This is a ethics base line over all of people and all of generations.

\subsection{System programming}

Sustainable cyberspace is a general system composed of several subsystems such as administration, legal system, supporting technology, human resources, and public participation and so on.

(1)Administrating

The administrating mechanism must be firstly established by integrated use of planning, law making, administrative means, economic policy and other measures. Thus, in the process of establishment it is possible to keep the decision-making program concord and scientific.

(2)Legal system 
In order to make more efficient control of security threats in cyberspace, information in cyberspace and natural resources can be forced to get fused into each other through an exclusive legal system for cyberspace. Under this legal system, more and more people will get used to the idea of win-win cooperation, which is supposed to promote sustainable development of economic society and ecological environment.

(3) Supporting technology

Constantly updated science, technology and infrastructure in cyberspace can effectively provide the decision-makers on various levels with scientific reasons. A series of supporting technologies for cyberspace development can improve the level of social governance, deepen people's understanding of the relationship between man and nature, and expand the scope of supply in the case of social, natural as well as cyber resources. Thus, there is bound to an increase of efficiency in resource utilization and economic benefits.

(4)Human resources

All people involved in the cyberspace should have a high level of knowledge, understanding the long-term influences and consequences of human activities in the nature and society. Furthermore, they should have a high level of morality, understanding their sublime responsibilities for future generations, so that they may sacrifice some immediate interests and local interests, when necessary for the long-term and global development.

(5)Public participating

The public and social organizations should widely participate in not only decisions about sustainable development of cyberspace, but also supervision on policy implementation process. In this way, the sustainability of cyberspace can get maintenance from most people.

\section{Conclusion}

At present, most of countries and regions in the world are more and more restricted by cyberspace development. International society is attaching more and more importance to various problems in cyberspace development, which is sure to form a pattern of competition and cooperation between countries. The concept of sustainability in virtual cyberspace might as well be, to some extent, a continuity of sustainability in physical space. It is believed that with the global governance system gradually perfecting, the concept of sustainability in cyberspace is certain to get more acceptance and maintenance from more countries and more people. 


\section{References}

1. Butlin, John (1989-04-01). Our common future. By World commission on environment and development. (London, Oxford University Press, 1987, pp.383.). Journal of International Development 1 (2): 284-287.

2. Manning, Stephen; Boons, Frank; Von Hagen, Oliver; Reinecke, Juliane (2012). National Contexts Matter: The Co-Evolution of Sustainability Standards in Global Value Chains. Ecological Economics 83: 197-209.

3. Reinecke, Juliane; Manning, Stephen; Von Hagen, Oliver (2012). The Emergence of a Standards Market: Multiplicity of Sustainability Standards in the Global Coffee Industry. Organization Studies 33 (5/6): 789-812. 